\title{
The Diagnostic Value of the Leukocyte Shift Index in Purulent-Septic Rhinosinusogenic Complications in Children
}

\author{
Tatiana B. Kuznetsova ${ }^{1}$; Maria N. Ponomareva ${ }^{1}, \mathrm{PhD}, \mathrm{ScD}$; \\ Nadezhda E. Kuznetsova ${ }^{1,2^{*}}, \mathrm{PhD}$ \\ ${ }^{1}$ Tyumen State Medical University; ${ }^{2}$ Tyumen Region Clinical Hospital No 2 \\ Tyumen, the Russian Federation
}

\begin{abstract}
The aim of this study was to investigate the diagnostic value of the leukocyte shift index (LSI) in inflammatory pathology of the paranasal sinuses (PNS) with the rhinosinusogenic orbital complications (RSOC) in pediatric patients.

Methods and Results: The study involved 50 patients ( 26 boys and 24 girls) with diseases of the PNS and RSOC (reactive edema of the eyelids, orbital tissue, and purulent-septic complications of the eyelids and orbit) aged from 1 to 17 years (mean age of $6.66 \pm 0.63$ years). Group 1 included 29 patients (16 boys and 13 girls) with reactive edema of the eyelids and orbital tissue. Group 2 included 21 patients (10 boys and 11 girls) with purulent-septic RSOC. As a marker for determining the activity of the inflammatory process and the disorders of the immunological reactivity of the body, LSI (leukocyte shift index) was calculated. In general, the LSI value was $1.61 \pm 0.21$ in Group 1 and $3.45 \pm 0.49$ in Group $2(P=0.001)$. Among patients aged between 3 and 12 years, the LSI was $1.66 \pm 0.30$ in Group 1 and $3.93 \pm 0.79$ in Group $2(P=0.012)$. The results obtained indicate that LSI can be used to predict purulent-septic RSOC in inflammatory diseases of PNS in patients aged between 3 and 12 years. LSI values from 1.36 to 1.96 may predict the development of reactive edema of the eyelids and orbital tissue; from 3.14 to 4.72 - the development of purulent-septic complications of the eyelids and orbit.

Conclusion: The results obtained can be useful in predicting the clinical course of the RSOC in inflammatory pathology of PNS in patients in the age group of 3-12 years. (International Journal of Biomedicine. 2021;11(3):301-304.)
\end{abstract}

Key Words: paranasal sinuses $\bullet$ rhinosinusogenic orbital complications $\bullet$ leukocyte shift index

For citation: Kuznetsova TB, Ponomareva MN, Kuznetsova NE. The Diagnostic Value of the Leukocyte Shift Index in PurulentSeptic Rhinosinusogenic Complications in Children. International Journal of Biomedicine. 2021;11(3):301-304. doi:10.21103/ Article11(3)_ShC.

\section{Abbreviations}

CT, computed tomography; LSI, leukocyte shift index; MRI, magnetic resonance imaging; PNS, paranasal sinuses: RSOC, rhinosinusogenic orbital complications.

\section{Introduction}

Currently, sinusitis is one of the most common ENT diseases in pediatric practice. Timely diagnosis of sinusitis and its complications is very important. ${ }^{(1)}$ Inflammatory diseases of the orbit in $40 \%-80 \%$ of cases are of rhinosinusogenic origin

*Corresponding author: Nadezhda E. Kuznetsova, PhD. Tyumen State Medical University. Tyumen, the Russian Federation. E-mail:kne61@mail.ru in adults and in $43 \%$ of cases in children. The prevalence of rhinosinusogenic orbital complications (RSOC), according to the data of the department of pediatric otolaryngology, is $12 \%$, requiring a multidisciplinary approach to the tactics of treating pediatric patients. ${ }^{(2)}$ Orbital complications rank first among all serious complications of acute sinusitis. ${ }^{(3,4)}$ The anatomical features of the paranasal sinuses (PNS), their direct connection with the orbit, contribute to the rapid development of formidable septic complications. ${ }^{(5)}$ In children, especially young children, diagnosis is often difficult, according to objective data and the results of additional research methods. 
The aim of this study was to investigate the diagnostic value of the leukocyte shift index (LSI) in inflammatory pathology of the PNS with the RSOC in pediatric patients.

\section{Materials and Methods}

The study involved 50 patients ( 26 boys and 24 girls) with diseases of the PNS and RSOC (reactive edema of the eyelids, orbital tissue, and purulent-septic complications of the eyelids and orbit) aged from 1 to 17 years (mean age of $6.66 \pm 0.63$ years). All patients were treated in the department of pediatric otolaryngology at the Regional Clinical Hospital No.2 of Tyumen in the period from 2018 to 2019. Group 1 included 29 patients (16 boys and 13 girls) with reactive edema of the eyelids and orbital tissue. Group 2 included 21 patients (10 boys and 11 girls) with purulent-septic RSOC. As a marker for determining the activity of the inflammatory process and the disorders of the immunological reactivity of the body, we chose LSI, ${ }^{(6)}$ calculated taking into account the parameters of the general blood test. ${ }^{(7)}$

The LSI value of $1.96 \pm 0.56$ is considered normal. The LSI values are influenced by the characteristics of the physiological state of the organism, depending on age (the first cross at 5 days and the second at 5 years).

All children were admitted on an emergency basis with complaints of difficulty in nasal breathing, redness, swelling of the eyelid skin, narrowing of the palpebral fissure, headaches, pain in the projection of the sinuses, unilateral disturbance of the outflow of discharge from the nose, hyperthermia, anxiety, and sleep disturbance. All children were examined by an otorhinolaryngologist, pediatrician, and ophthalmologist, as well as by a neurologist, anesthesiologist, and neurosurgeon, according to the indications. Upon admission, patients underwent clinical and laboratory diagnostics, radiography, and CT, as well as MRI of the PNS, orbit, and brain, according to indications. CT or MRI with contrast was performed for diagnostic purposes to exclude intraorbital and intracranial complications. Surgical treatment of the PNS diseases (catheterization, endoscopic sinusitis, orbitotomy) was performed according to indications. A course of intensive antibiotic therapy, heparin therapy, and local therapy was carried out.

Statistical analysis was performed using the statistical software STATISTICA (v10.0, StatSoft, USA). The normality of distribution of continuous variables was tested by onesample Kolmogorov-Smirnov test. Continuous variables were presented as mean \pm SEM. Means of 2 continuous normally distributed variables were compared by independent samples Student's $t$ test. A value of $P<0.05$ was considered significant.

The study was conducted in accordance with ethical principles of the WMA Declaration of Helsinki (1964, ed. 2013) and approved by the Tyumen State Medical University Ethics Committee. Written informed consent was obtained from the patient/parent/guardian/ relative of each patient.

\section{Results and Discussion}

In the present study, in general, the LSI value was $1.61 \pm 0.21$ in Group 1 and $3.45 \pm 0.49$ in Group $2(P=0.001)$.
However, a comparative analysis of LSI in the two groups, according to the age subgroups, did not show significant differences (Table 1, due to the small number of observations, but revealed significant fluctuations in this indicator: from 0.75 to 1.83 in Group 1 and from 1.88 to 4.65 in Group 2 . In addition, in patients in the age subgroup of 1-2 years, this indicator was not informative in terms of predicting the development of the RSOC: rhinogenic reactive edema of the eyelids and orbital tissue developed with LSI of $1.54 \pm 0.23$, and septic complications of the eyelids and orbit - with LSI of $1.88 \pm 0.53(P>0.05)$.

Table 1.

LSI values in Croups 1 and 2 according to the age subgroups

\begin{tabular}{|c|c|c|c|c|c|}
\hline \multirow{2}{*}{$\begin{array}{c}\text { Age } \\
\text { subgroups } \\
\text { (yrs) }\end{array}$} & \multicolumn{2}{|c|}{ Mean age, yrs } & \multicolumn{2}{|c|}{ LSI } & P-value \\
\cline { 2 - 6 } & Group 1 & Group 2 & Group 1 & Group 2 & \\
\hline $\begin{array}{c}1-2 \\
(\mathrm{n}=9)\end{array}$ & $\begin{array}{c}1.71 \pm 0.20 \\
(\mathrm{n}=7)\end{array}$ & $\begin{array}{c}1.04 \pm 0.17 \\
(\mathrm{n}=2)\end{array}$ & $1.54 \pm 0.23$ & $1,88 \pm 0.53$ & 0.714 \\
\hline $\begin{array}{c}3-4 \\
(\mathrm{n}=15)\end{array}$ & $\begin{array}{c}3.55 \pm 0.17 \\
(\mathrm{n}=12)\end{array}$ & $\begin{array}{c}3.67 \pm 0.23 \\
(\mathrm{n}=3)\end{array}$ & $1.67 \pm 0.48$ & $4.65 \pm 1.32$ & 0.055 \\
\hline $\begin{array}{c}5-7 \\
(\mathrm{n}=7)\end{array}$ & $\begin{array}{c}5.80 \pm 0.42 \\
(\mathrm{n}=3)\end{array}$ & $\begin{array}{c}5.75 \pm 0.55 \\
(\mathrm{n}=4)\end{array}$ & $0.75 \pm 0.01$ & $2.86 \pm 1.35$ & 0.193 \\
\hline $\begin{array}{c}8-12 \\
(\mathrm{n}=8)\end{array}$ & $\begin{array}{c}9.80 \pm 0.82 \\
(\mathrm{n}=5)\end{array}$ & $\begin{array}{c}9.5 \pm 0.99 \\
(\mathrm{n}=3)\end{array}$ & $1.83 \pm 0.44$ & $4.63 \pm 2.19$ & 0.265 \\
\hline $\begin{array}{c}13-17 \\
(\mathrm{n}=11)\end{array}$ & $\begin{array}{c}14.0 \pm 1.41 \\
(\mathrm{n}=2)\end{array}$ & $\begin{array}{c}14.29 \pm 0.45 \\
(\mathrm{n}=9)\end{array}$ & $1.77 \pm 0.12$ & $3.26 \pm 0.22$ & 0.061 \\
\hline
\end{tabular}

Particular attention should be paid to LSI indicators in the age group of 3-12 years. The data obtained indicate that children at this age are more likely to suffer from inflammatory diseases of the PNS and have RSOC. Thus, among patients aged between 3 and 12 years, the LSI was $1.66 \pm 0.30$ in Group 1 and $3.93 \pm 0.79$ in Group $2(P=0.012)$. The results obtained indicate that LSI can be used to predict purulent-septic RSOC in inflammatory diseases of PNS in patients aged between 3 and 12 years. LSI values from 1.36 to 1.96 may predict the development of reactive edema of the eyelids and orbital tissue; from 3.14 to 4.72 - the development of purulent-septic complications of the eyelids and orbit. LSI values can complement a number of criteria for determining the indications for early surgical intervention and, the extent of it, as well as for the prevention of intraorbital and intracranial complications. To demonstrate the possibility of using LSI, we present two clinical cases.

\section{Case Presentation 1}

A 10-year-old girl was admitted on 11.26 .2018 to the department of pediatric otolaryngology for emergency indications. Complaints: nasal congestion, edema of the lower and upper eyelids of the right eye.

Anamnesis morbi

According to the mother's words, the child fell ill on 
11.23.2018, when swelling of the eyelids of the right eye appeared against the background of a purulent runny nose. Vasoconstrictor nasal drops were used in the treatment. According to her mother, following the treatment, the runny nose stopped.

Anamnesis vitae

Child from second pregnancy, first childbirth, delivery at term. Body weight at birth $-3600 \mathrm{~g}$. Scheduled vaccinations. The patient grew and developed according to her age. Past diseases: acute respiratory infections, chickenpox. History of allergies is not burdened.

\section{Clinical Findings, Diagnostic Assessment, and Treatment}

General condition is moderate. Consciousness is clear. Body temperature $-36.6^{\circ} \mathrm{C}$. The mucous membranes are clean and moist. The skin cover is clean, physiological color. Tongue is pink and moist. Pharynx: mucous membranes are pink and clear; the soft palate is mobile, with no plaque. The lymph nodes are intact. No peripheral edema. The respiratory rate -26 breaths per minute. The heart rate is $84 \mathrm{bpm}$. The abdomen is soft; the liver and spleen are not palpable. Urination is not disturbed. The stool is normal.

Right eye: The palpebral fissure is sharply narrowed. Edema, hyperemia of the upper and lower eyelids. The eyeball is fully mobile.

Nose: With anterior rhinoscopy on the right, the nasal mucosa is hyperemic, sharply edematous; in the nasal passages, there is scanty free discharge on the right, pronounced edema of the mucous membrane of the inferior turbinate; breathing is difficult. With anterior rhinoscopy on the left, the mucous membranes of the nasal conchas are pink, common nasal passage is visible, there is mucous discharge. The nasal septum lays along the midline.

Ears: AS and AD: The eardrum is gray, the cone of light is preserved, and the identification markings are visible.

LSI-1.8.

Ophthalmologist's examination: "Acute maxillary sinusitis. Reactive edema of the eyelids of the right eye."

This clinical case indicates that the value of ISL of $1.8 \mathrm{U}$ in purulent-inflammatory disease of the PNS is associated with the development of reactive edema of the eyelids.

\section{Case Presentation 2}

A 5-year-old boy was admitted to the department of pediatric otolaryngology on April 30, 2018, for emergency indications. Complaints: difficulty in nasal breathing, headache, fever $\left(39.0^{\circ} \mathrm{C}\right)$, redness and edema of the right eyelids, narrowing of the palpebral fissure on the right, protrusion of the right eye anteriorly out of the orbit.

\section{Anamnesis morbi}

According to the mother, the child fell ill on 24.04.18, when a runny nose and difficulty in nasal breathing appeared. On the day of admission, there was a headache, swelling of the eyelids of the right eye, the eye is closed, temperature of $39^{\circ} \mathrm{C}$. Anamnesis vitae

Child from full-term pregnancy, body weight at birth - 3800g. The patient grew and developed according to his age. Scheduled vaccinations. Past diseases: acute respiratory infections. History of allergies is not burdened.

Clinical Findings, Diagnostic Assessment, and Treatment
Body weight is $23 \mathrm{~kg}$. The general condition is severe, due to the underlying disease, and symptoms of intoxication. Consciousness is clear. Body temperature $-39.0^{\circ} \mathrm{C}$. The mucous membranes and skin cover are clean. Tongue is pink and moist. Pharynx: mucous membranes are pink and clear; the soft palate is mobile, with no plaque. Submandibular lymph nodes are enlarged up to $2 \mathrm{~cm}$, moderately painful. The respiratory rate -26 breaths per minute. The heart rate is 100 bpm. Breathing through the nose is difficult. The vesicular breathing is heard over the thorax. Heart sounds are sonorous, rhythmic. The abdomen is soft; the liver and spleen are not palpable. Urination is not disturbed. The stool is normal.

Right eye: Edema, infiltration of the eyelid skin. The eye slit is sharply narrowed, the eyeball is marked by restriction of mobility, exophthalmos.

Nose: The nasal breathing is difficult: pronounced swelling of the mucous nasal concha on the right, no discharge. On the right, the mucous membrane of the turbinates is sharply hyperemic, the nasal passage is narrowed; there is no free discharge. The nasal septum is in the middle position.

Oropharynx: Mucous membranes are pink and clear, with no plaque. Palatine tonsils of normal size.

Ears: The shape and size of the auricles, parotid and mastoid areas on both sides are not changed. External auditory canals are not changed; there is no discharge. The eardrum of $\mathrm{AS}$ and $\mathrm{AD}$ is light gray, the cone of light is preserved, and the identification markings are visible.

LSI $=4.0$. The patient was examined by ophthalmologist, maxillofacial surgeon, pediatrician, anesthesiologist, and neurologist. Clinical diagnosis: "Acute right-sided purulent polysinusitis. Rhinogenic phlegmon of the right orbit." Surgical treatment: endoscopic polysinusotomy, orbitotom. A course of antibiotic therapy, heparin therapy, and local treatment was carried out.

This clinical case indicates that the value of ISL of 4.0 in purulent-inflammatory disease of the PNS was associated with the development of purulent-septic complication - orbital phlegmon.

The presented patients were discharged with recovery under the supervision of an ENT doctor on an outpatient basis.

\section{Conclusion}

Domestic scientists have shown the role of leukocyte indices in assessing the body's immunological reactivity, the severity of endogenous intoxication, and its complications. ${ }^{(7,8)}$ This study demonstrates the diagnostic significance of LSI in predicting the clinical course of the RSOC in inflammatory pathology of PNS in patients in the age group of 3-12 years. The development of reactive edema of the eyelids and orbital tissue is predicted when the LSI is from 1.36 to 1.96; purulentseptic lesions of the eyelids and orbital tissue- from 3.14 to 4.72 .

The results obtained can be useful in providing specialized medical care for children of this age group, for optimizing the algorithms for preventive examinations and therapeutic interventions, and for offering the possibility of predicting the severity of the disease and timely surgical treatment of RSOC in the patients with inflammatory pathology of PNS. 


\section{Competing Interests}

The authors declare that they have no competing interests.

\section{References}

1. Abdikhalikov ZhA, Anarbaev AA, Aybashov KhA, Usmanov DU. [Sinusogenic orbital complications in children]. Russian Bulletin of perinatology and pediatrics. 2016;61(4);264.[Article in Russian].

2. Kuznetsova TB, Yolshin VN, Kuznetsova NE, Ponomareva MN. [Prevalence of rhinosinusogenic orbital complications in children of the Tyumen region]. Bulletin of the Bashkir State Medical University. 2019; (3):97-101. [Article in Russian].

3. Gulyaeva LV, Zolotareva MA. [Features of orbital rhinosinusogenic complications in childhood]. Tavrichesky Medical and Biological Bulletin. 2016;19(1):16-18. [Article in Russian].

4. Bogomilskiy MR, Chistyakova VR. Pediatric Otorhinolaryngology: A Guide for Physicians. Vol. 1. M.: "Meditsina"; 2005. [In Russian].
5. Kuznetsova NE, Kuznetsova TB, Ponomareva MN. [Clinical characteristics of reactive orbital complications in children with purulent-inflammatory pathology of the paranasal sinuses]. Proceedings of the International Congress "Man and Medicine. Ural - 2019," Tyumen, 2019:4546. [Article in Russian].

6. Ivanov DO, Shabalov NP, Shabalova NN, Kurzina EA, Kostyuchek IN. [Leukocyte indices of cellular reactivity as an indicator of the presence of hypo- and hyperergic variants of neonatal sepsis]. Available from: http://www.medlinks.ru/ article.php?sid=22330.[Article in Russian].

7. Mustafina ZhG, Kramorenko IuS, Kobtseva VIu. [Integral hematological indices in assessing body immunological reactivity in patients with ophthalmic pathology]. Klin Lab Diagn. 1999 May;(5):47-9. [Article in Russian].

8. Speransky II, Samoilenko GE, Lobacheva MV. [Complete blood count - are all of its possibilities exhausted? Integral indices of intoxication as criteria for assessing the severity of endogenous intoxication, its complications, and the effectiveness of treatment]. Acute and Emergency Conditions in the Practice of a Doctor. 2009.19(6):5. [Article in Russian]. 